\title{
Delayed Referral of Children with New Onset Type 1 diabetes
}

\section{lyer D, Choudhary D, Agwu JC Sandwell and West Birmingham NHS Trust}

\section{Background}
Type 1 diabetes (T1D) is characterised by autoimmune destruction of pancreatic beta cells leading to insulin deficiency.
Prompt referral and treatment is important to prevent diabetic ketoacidosis (DKA) which remains the commonest cause of death in this condition. The recently published NICE guidelines (NG18) recommends that Primary Care staff 'refer children and young people with suspected type 1 diabetes immediately (on the same day)'
to a multidisciplinary paediatric diabetes team with the competencies needed to confirm diagnosis and to provide immediate care.

\section{Aim}

To audit the timeliness of referrals of children with suspected T1D to paediatric diabetes team, as well as reasons for any delay.

\section{Method}

Retrospective case notes review of children diagnosed with diabetes mellitus (DM) between 1st January 2005 and 31st December 2014 and managed by Sandwell Paediatric Diabetes service.

We reviewed demographic data, information on source of referral, date of initial presentation to a health care professional, date of insulin initiation, cause of delayed presentation (where applicable), date of initial diagnostic blood tests and mode of presentation.

Statistical analysis was carried out using Minitab 17

\section{Results}

117 children were diagnosed with diabetes in the study period Twenty one were excluded as

- $9(7.7 \%)$ had T2DM,

$1(0.85 \%)$ had glucokinase deficiency and

$11(9.4 \%)$ children were diagnosed elsewhere and transferred later to our service.

Ninety six children with T1D were included in the study.

\begin{tabular}{|l|l|}
\hline \multicolumn{1}{|c|}{ Characteristics } & \multicolumn{1}{c|}{ Children $\mathrm{n}=\mathbf{9 6}$} \\
\hline Males $\mathrm{n}(\%)$ & $49(51.05 \%)$ \\
\hline Females $\mathrm{n}(\%)$ & $47(48.95 \%)$ \\
\hline Mean age at referral age(SD) & 8.6 years (SD+/-3.8 years) \\
\hline
\end{tabular}

\section{Distribution by Ethnicity}

\section{Ethnicity}

White British

$68(70.83)$

Asian

Afrocarribean

Mixed

Not stated

\section{Source of referral}

\begin{tabular}{|c|c|}
\hline GP n (\%) & $55(59.14 \%)$ \\
\hline ED $n(\%)$ & $24(25.81 \%)$ \\
\hline
\end{tabular}

\section{Presentation in DKA}

- Thirty three $(34.37 \%)$ children presented in DKA.

- In a regression analysis, presentation in DKA was significantly associated with younger age at presentation $(p=0.033)$ and delay in referral $(p=0.01)$.

- There was no significant association between DKA at presentation and sex, ethnicity, family history of DM or source of referral.

\section{Delay in referral}

There was a delay in referral in 35 (36.54\%) children. Mean duration of delay in presentation was 2.96 days (SD+/-3.183 days).

\section{Nineteen $(79.17 \%)$ of these children presented in DKA}

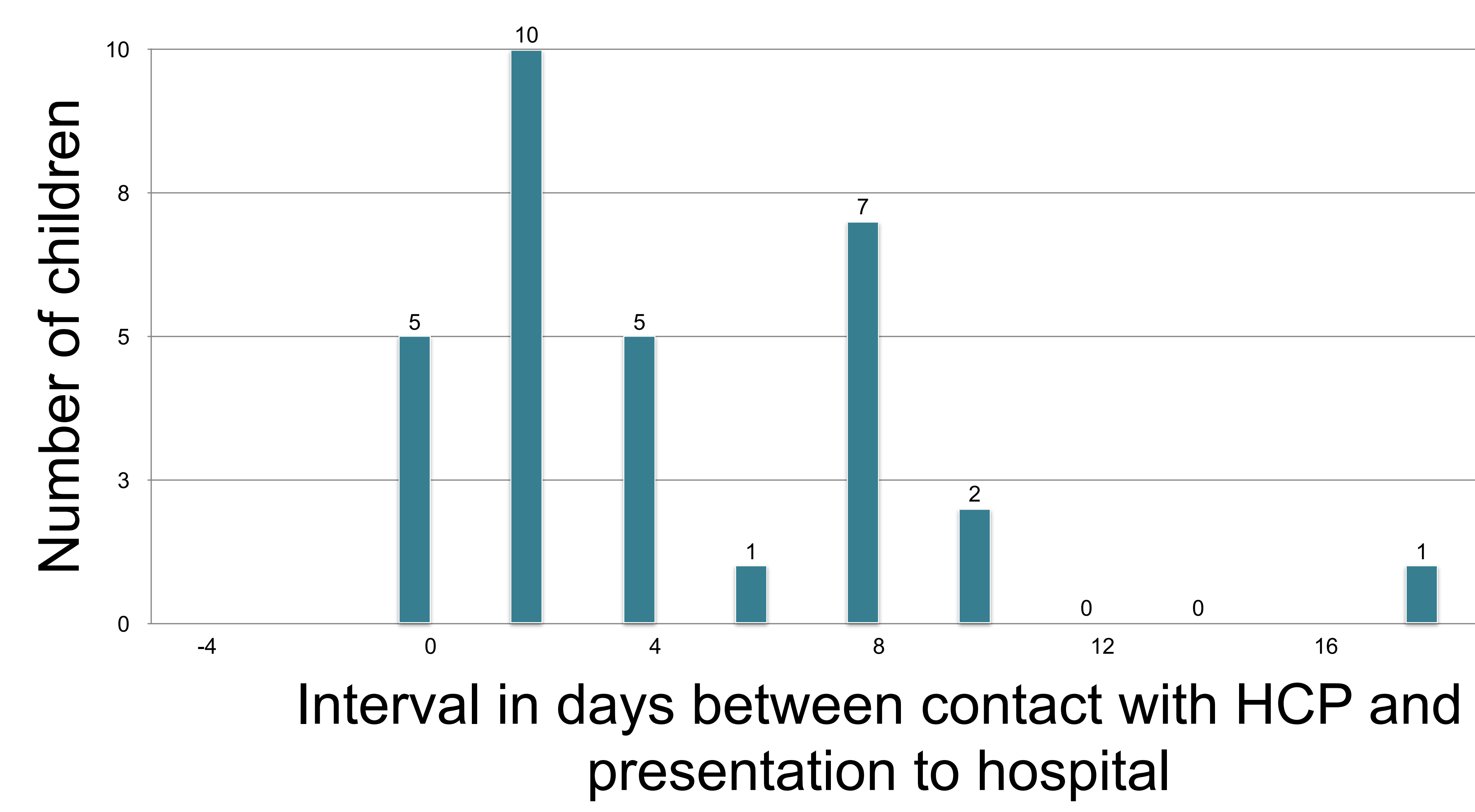

\section{Reasons of delay}

The commonest reason for delayed presentation was delayed referral due to GP requesting fasting blood glucose in 25 $(71.43 \%)$.

The other reason for delay was misdiagnosis 10 (28.57\%), commonly being urinary tract infection, viral illness and thrush.

\section{Conclusion}

- Our audit confirms that delay in referral of children with suspected T1D to paediatric diabetes team is commonly due to fasting blood glucose being arranged.

- Primary health care professionals should be provided with regular education regarding childhood diabetes and its diagnosis to prevent delay in referral and diagnosis.

\section{-All CCG should have Primary care referral guidelines stressing need to refer on the basis of suspicion and perhaps point of care BG only.}

References

1. National Institute for Health and Clinical Excellence (NICE). Diabetes (type 1 and type 2) in children and young people: diagnosis and management. August 2015. NG 18. Available from http://www.nice.org.uk/guidance/ng18 (Accessed 22 October 2015) 